\title{
The News Media Outlet is the Message
}

\author{
Hyun J ung Yun (Ph.D.) \\ Texas State University, US \\ hy12@txstate.edu
}

Blake Farrar (M.A.)

Texas State University, US

bf18@txstate.edu

\begin{abstract}
At the time of its inception, "the medium is the message" by Marshall McLuhan (1964) was both prophetic and controversial. A half-century later, with innovative broadcasting technologies leading to a massive scale media market, the concept of a singular "medium" seems too broad to understand theoretical patterns of political communication. This study proposes a new phrase, "the news media outlet is the message," and examines the differing effects of news media outlets for partly-mediated political communication. The experimental study measured changes in voters' candidate evaluations before and after watching each of the three real-time televised debates in the 2012 American presidential election. The participants, who were randomly assigned to and viewed the debates via one of the five different news media outlets, showed a clear media channel effect on their evaluations of political candidates in partly-mediated forms of political discourse, and it confirmed that the news media outlet was indeed the message.
\end{abstract}

Keywords: news media outlets; televised presidential debates; candidate evaluation

\section{Introduction}

The iconic phrase, "the medium is the message," by Marshall McLuhan (1964) is uniquely embedded in the scholarly and practical works of political communication. A half-century later, with innovative broadcasting technologies leading to a massive scale media market, the concept of a singular "medium" seems too broad to understand theoretical patterns of political communication. This study proposes a new phrase, "the news media outlet is the message," and examines the differing effects of news media outlets for partly-mediated political communication.

People are often unaware of variances in political coverage across different news media outlets for partly-mediated political events, such as press conferences and candidate debates. Nevertheless, each news outlet utilizes different methods to fit its own political interests and intentions into the broadcast in order to meet the expectations of its target audiences and differentiate it from other competitors. This study compares the effects of visual editing techniques utilized to broadcast political debates by five different media outlets, CNN, FOX, PBS, CBS, and C-SPAN, on voters' candidate evaluations. Specific attention is paid to changes in candidate evaluations by voters before and after watching each of the three real-time televised debates sponsored by the Commission on Presidential Debates in the 2012 presidential election via each of the five channels.

The current study suggests that partisan media outlets embed their political intentions via broadcasting strategies, which significantly impact viewers' perceptions of the 
political subjects in target audiences. News media outlets produce a measureable effect on voters' evaluations of their candidates in partly-mediated forms of political discourse, suggesting that in the current information landscape the news media outlet is the message.

\section{Theoretical Underpinning Medium is the Message Reconsidered}

McLuhan posited that in all cases the medium of communication impacts societies far more than the informational content of any particular media (McLuhan, 1964). In his famous publication, "The Medium is the Massage," McLuhan argued that by shifting our environment, medium is able to alter our perceptions and by doing so change the way we perceive reality (McLuhan, Fiore, \& Agel, 1967, p. 41). McLuhan sees media as a means of "arranging the entire human environment as a work of art" and believes it is likely that audience members are not always fully aware of the true impact of this craft as the "patterns of environments elude easy perception" (McLuhan et al., 1967, p. 69). Modern electronic technologies undoubtedly possess the ability to connect us to political events, where differences in time and space are diminished. Although audiences often participate in "simultaneous happenings" (McLuhan et al., 1967, p. 69), one must consider the channel through which that event is broadcast.

McLuhan argues that the shift to visual media forces us to abandon the individualistic and fragmented outlook previously accentuated in print media, in favor of a more globalized world-view. As printed media fashioned a varied public open to personal interpretation, in turn electronic technology shaped the potentially wider mass audience subject once again to the interpretation of the message broadcaster. This global village mentality created by modern media, he argued, reignites primordial sensations, eliciting "tribal emotions" instantaneously as we process information (McLuhan et al., 1967, p. 63). However, he failed to envision the possibility that groups would coalesce around a particular, fragmented viewpoint based on ideological preference emanating from opposing outlets of information. Perhaps McLuhan could not have envisioned a single movie or television show broadcast simultaneously on a dozen different channels, each with varying angles, differing audience shots, altered character juxtapositions and scrolling bits of preselected information intended to impact viewer perceptions.

The extent to which media is able to impact our thoughts and actions lies at the heart of much debate within the discipline of communication theory, but it may also determine the outcome of our political futures as well. The role media editing techniques played in the first presidential debate of 2012 is a great example of the impact on public perception. Viewers' perceptions of candidate performances were significantly impacted by the use of split screen shots showing each candidate's actions when not actively answering questions. Audience members and pundits alike picked up on Barack Obama's detached demeanor while Romney spoke, resulting in increased negative attitudes about Obama (Peters, 2012). In fact, recent presidential debates provide numerous examples of candidates caught on camera in situations that impact perceptions negatively and research suggests that this split screen technique may especially affect onlookers' opinions of candidates they oppose (Scheufele, Kim, \& Brossard, 2007). Presidential debates between political parties, leading up to the general election, happen very late in the campaign process. At this point many voters already possess a preference for one candidate or the other (David \& Peter, 1991, p. 48), however all voters including undecided voters are potentially swayed in manners that may impact them whether or not they are aware. Presidential debates are among the most viewed events in the United States, falling somewhere between the Super Bowl and the Academy Awards in terms of television ratings (Schroeder, 2008, p. 282). The first presidential debate of the 2012 campaign was broadcast on over 12 different media outlets and roughly 67 million viewers tuned into to watch. While that was the most viewed debate, still approximately 
65.6 million tuned in for the second debate broadcast over the same 12 networks and about 59.2 million tuned in for the final debate broadcast on 11 networks (Nielsen Media, 2012).

These televised presidential debates occur with such regularity in U.S. elections that it is as hard to imagine a campaign without debates, as it is an NFL football season without the Super Bowl. Broadcast debates possess such a ritualistic quality about them that they carry significance beyond informing voters on the platform positions of the candidates (Morley, 2004). Sociologists and anthropologists argue that rituals such as these provide greater symbolic meaning for society (Durkheim, 1995, p. 227). Ceremonial events often reinforce core beliefs among groups who participate, and debates likely provide an opportunity for partisan reaffirmation. If ceremonies such as political debates are transformative in nature, it is not surprising to expect some level of change to occur in the feelings of viewers.

Given the considerable number of viewers tuning in for presidential debates, these events afford significant opportunity for media outlets to impact voter perception. While many voters may tune in out of a sense of duty or responsibility, many likely watch the debate for the drama and spectacle of entertainment (Kraus, 1988, p. 77). Former President Richard Nixon commented that presidential debates probably do not "serve a responsible role in defining issues," because the medium of television places a "greater premium on showmanship than statesmanship" (Nixon, 1978, p. 221). Regardless of the ability of presidential debates to inform voters on the specifics of policy issues, there is no doubt that the media will continue to take advantage of the events for current and future campaigns. There is also no evidence to counter the belief that the public will continue to tune in to the spectacle, "permitting the media to take advantage of us" (Commager, 1960) and allowing the political candidates to seek to convey a message that may or may not be consistent with the media outlet's agenda.

\section{Media Broadcasting Techniques}

Research into television's role in shaping audience perceptions of candidate performance and therefore electability dates back to the very first televised presidential election between Richard Nixon and John F. Kennedy in 1960 (Lang, 1968). The shift from broadcasting debates over the radio to televised debates opened up a world of potential for media to impact these partially-mediated events, but it also requires researchers to study these impacts. Previous research on political debates focused on radio broadcasts and print media transcripts and analyses. These inquires examined the audible performance of candidates, but the visual elements of television dwarf the verbal aspects of television in many respects (Hellweg, Pfau, \& Brydon, 1992, p. 72). McLuhan believed that electronic, televised information demands a much deeper type of participation and involvement, by including the visual sense (McLuhan et al., 1967, p. 69). However, given current research it is debatable whether or not this transition is towards a truly deeper type of audience involvement or rather a regression back to a more primitive, insincere interpretation of political communication.

Some of the early research into television media techniques for presidential debates scrutinized camera shots, attempting to determine if either Carter or Ford was given uneven visual presentations in the 1976 presidential debates. This analysis compared the amount of screen composition, camera angles, and eye contact with the camera and smiling shots (Tiemens, 1978). Although researchers debate whether or not any preference was given to either candidate (Davis, 1978), the fact that they began research in this area helped establish methods for researching the role of television editing in presidential debates. Following this analysis, others began examining the same debates and noted the use of editing techniques to depict clash between the candidates. They argued that by using shorter screen shots to cut back and forth between 
candidates for reaction shots and by utilizing two-shot techniques that include both candidates or spilt screens of both candidates they could visually portray the appearance of greater conflict between the candidates (Messaris, Eckman, \& Gumpert, 1979). McLuhan himself hinted at the impact of such media techniques when he mentioned the innovations in film editing of his time, suggesting that audiences become preconditioned by television "to abrupt zooms, elliptical editing, no story lines, and flash cuts" (McLuhan et al., 1967, p. 128).

Researchers began combining analyses of both verbal and visual clash to develop a more integrated inquiry of the use of editing techniques. These studies indicate discrepancy often exists between verbal and visual content, suggesting that visual editing techniques can be used to elicit clash when verbal conflict is not occurring, or to overemphasize the clash when it is taking place. The opposite may also be true, editing techniques can be used to diminish the amount of verbal clash between candidates (Tiemens et al. 1985). In other instances, studies suggest that media techniques can potentially play a reduced role and can present the candidates on very even footing, using techniques consistently to present equal treatment (Hellweg \& Phillips, 1981).

Also significant is that fact that between the 1976 and 1988 presidential debates, the rapidity of screen shots doubled, or in other words the time between switching camera angles was cut in half. The same researchers also note that the panelists' or moderators' presentation on screen increased over the same time period (Morello, 1988a, 1988b, 1992). These changes in the arrangement of images audiences experience while viewing debates should not be ignored, as research suggests the spatial context, including changes in screen shots, camera angles and the placement of visual cues on screen, significantly affect the viewers' recall of information gathered from the media (Rothkopf, Dixon, \& Billington, 1986). While some argue presidential debates only result in incremental changes in political knowledge regarding the candidates' positions on issues in the viewers (Holbrook, 1999), what might be more influenced by the media techniques are the relative perceptions of the candidates within the audience.

\section{Media Outlet Partisanship}

A large segment of American society considers the media to be biased in one political direction or the other (Schneider \& Lewis, 1985). However, for media to be truly biased it must meet certain criteria. While there is debate over how bias is determined, for our purposes we will focus on a couple narrow aspects of media bias. For example, in order for media bias to be important and worth studying it must be persuasive enough to have a measurable impact on the viewer. If the media does not influence audience perception with noticeable effects, then it is not relevant to politics or electoral outcomes. Additionally, media bias needs to be persistent over time and sustained in order to have an impact, rather than occurring momentarily or over a brief period of time (Williams, 1975). While the extent of the bias and the impact of the bias are up for debate, recent meta-analysis does suggest that television networks exhibit some media bias, more so than newspaper media, when reporting the news. This bias may be small in some instances, but it is measurable when considering which stories the channels chose to cover as well as the statements made during the news coverage (D'Alessio \& Allen, 2000).

Although public certainty of media bias exists, it may be that the public perceives media bias to be much stronger than it actually is. This is especially true when the bias challenges a given audience's political preference (Stevenson \& Greene, 1980). One cause of perceived bias is selective perception, where different viewers witness the same political event but come away with very different interpretations of the episode (Hastorf \& Cantril, 1954). Early studies done on this topic tend to treat the media as a whole, asking generally if people think "the media" favors a particular candidate or another 
(Media Studies Center-Roper Center, 1996), as opposed to focusing on the perception of bias at the network level. However, with the growth in new forms of opinionated media outlets, research at the network level is proliferating rapidly.

Niche media outlets, most notably cable networks such as FOX and MSNBC, are characterized by the presence of news anchors expressing a particular political viewpoint. This retreat from traditional journalism with an emphasis on "balance and editorial separation" (Project for Excellence in Journalism, 2007) tends to focus increasingly not just on providing information and entertainment, but doing so based on clear ideological assumptions while advancing a specific agenda (Entman, 2005). This trend toward biased journalism is more prevalent on cable networks than on network news shows. Approximately $52 \%$ of news stories on the cable news channels like CNN, MSNBC and FOX provide only one view when discussing controversial political issues compared to $20 \%$ on major network channels. Journalistic opinions also occur much more frequently on cable networks than on public broadcasters' programs such as PBS news. (Project for Excellence in Journalism, 2005). This swing towards politically biased cable media seems to be largely due to the fact that it is good for business. This strategy appears successful in drawing ratings (Carpenter, 2006) in a time where audience members increasingly select media outlets that reinforce their own personal political leanings (Iyengar \& Hahn, 2009).

When looking at the news coverage of media outlets during the course of the 2012 presidential campaign, both Barack Obama and Mitt Romney garnered more negative coverage than positive treatment in news media. Research suggests that Obama benefited from an early advantage in terms of the amount of coverage compared to Romney, but as the electoral calendar progressed coverage became relatively equal during the later part of the campaign (Pew Research Center, 2012, p. 2). While both candidates received more negative coverage overall, some networks appear to show a clear bias in the amount of negative or positive coverage provided.

MSNBC and FOX appear to stand out in terms of disproportionately negative coverage of one candidate over the other, with MSNBC being the most one-sided. It is not surprising as both networks arguably construct themselves around a particular ideological viewpoint. The amount of negative coverage for Obama on FOX was $46 \%$ and the positive coverage only $6 \%$, resulting in an 8-to-1 ratio of negative to positive coverage. As for MSNBC, the amount of negative coverage for Romney was $71 \%$ and just $3 \%$ positive coverage, resulting in a 23-to-1 ratio of negative to positive coverage (Pew Research Center, 2012, p. 4). This ideological gulf was also apparent in the 2008 presidential election between John McCain and Barack Obama, however the disparity between positive and negative coverage on both channels became more distinct in 2012 . This consistency over times confirms a persistent and likely intentional ideological bias by both networks (Pew Research Center, 2012, p. 19).

As far as positive coverage on both networks, when covering Obama MSNBC ran $39 \%$ positive stories and only $15 \%$ negative. FOX on the other hand ran $28 \%$ positive stories for Romney and $12 \%$ negative. While FOX and MSNBC were the most extreme in their disparity in coverage, $\mathrm{CNN}$ and $\mathrm{ABC}$ also presented Obama with more favorable coverage. While CNN provided Obama with $18 \%$ positive to $21 \%$ negative coverage, they covered Romney with an $11 \%$ positive to $36 \%$ negative coverage. Similarly, ABC provided $27 \%$ positive to $20 \%$ negative coverage of Obama and Romney with $18 \%$ positive to $33 \%$ negative (Pew Research Center, 2012, p. 19). This data supports the argument that cable new channels tend to present considerably more ideological based coverage of presidential elections over the course of the campaign.

Given this analysis, FOX seems to be the only channel with a clear Romney bias, while CNN, MSNBC and ABC present varying degrees of positive bias towards Obama or 
against Romney. As for the other major broadcast networks studied, CBS and NBC both provide very similar positive to negative ratios for both Romney and Obama. While both CBS and NBC both deliver more negative coverage of each candidate, they did not appear to show a significant preference for either Obama or Romney (Pew Research Center, 2012, p. 23). This again suggests that major broadcast networks present less biased coverage compared to cable networks.

\section{Impact of Partisan Media Broadcasting Techniques on Viewers in Partly- Mediated Political Communication}

Although there is a trend among cable networks to present news in a bias manner, presidential debates remain unique media events in that news channels are unable to directly input verbal commentary or coverage analysis while the debates occur. This largely prevents networks from interjecting what is referred to as "statement bias" (Hofstetter, 1976), or exclaiming ideological opinions during the proceedings. However, networks increasingly use banners or supplementary information on screen to provide additional stimuli to viewers. At the most basic level, networks often display the name and party of a candidate on the bottom of the screen or the name of an audience member asking a question in a town hall style debate.

While this treatment seems banal, networks can also use more sophisticated ways to impact how audience members experience the debates. For example, some networks display audience or mediator questions in a banner along the bottom of the screen to frame the topic for the viewing audience. If a candidate veers of topic this might be a trigger to the audience, indicating the candidate is off topic and evading the question. On the more extreme end of this spectrum, news networks can show a live focus group rating to show how a select collection of potential voters respond to candidate statements in real time. This rating may be divided between male and female categories or possibly between political parties. It is possible that viewers react to the ratings provided by the network and unconsciously agree with the focus group response. As this is a recent technique, more study is required into the role these elements play in the psychological process and impact on voter perception.

Another form of media bias referred to as "gatekeeping" occurs when news channels select specific stories to report based on an established ideological basis or agenda (White, 1950). Unless it is the host network, the channel maintains no control over the questions or topics discussed during the debate, so the media channels cannot play a genuine gatekeeper role. For the most part, networks are limited to showing the debate as it occurs in real time and in full. However, there are many ways that the networks can impact how viewers perceive the debate through the editing techniques and other onscreen animations. Some networks display "facts" of their choice on screen to provide viewers with additional information on candidates' policy stance or past actions in office. This selection and display of facts is equivalent to both gatekeeper and statement bias in many regards.

Finally, "coverage bias" in the media generally refers to the amount of actual coverage each side gets in the media (Stempel \& Windhauser, 1989). In print media, coverage bias is usually gauged by the amount of words or space provided in columns, the number of headlines covering a candidate and the amount of visual images such as pictures (Klein \& Maccoby, 1954). In television media the measurement tends to be overall length of coverage provided on screen (Doll \& Bradley, 1974). With regard to televised presidential debates, coverage bias can be translated to the amount of time on screen as well as favorable screen shots provide by the network. There are several purposive techniques that television networks can use to impact how audience members perceive the debate. Different camera angles and favorably bigger and longer close-up shots can be the examples. These subtle changes in camera angle and candidate 
perspective may not appear consciously meaningful to the viewing audience as influential factors in the debate presentation, however previous research proposes it profoundly impacts the viewers' experience (Grabe \& Bucy, 2009).

\section{Research Framework and Design}

The purpose of the study is to examine the effects of the various techniques and strategies partisan media outlets utilize to differentiate partly-mediated political information. People often believe that media outlets cannot reframe or change partlymediated political contents such as press conference or campaign debates. However, partisan media outlets not only deliver the news through their chosen political filter but also easily color the meaning of those seemly fixed political contents. The definition of partisan media is still controversial and unsettled. However, as previous studies consistently employ, the current study borrowed the examples of the partisan media, treating CNN as a liberal and FOX as a conservative news outlet for a better reliability (Iyengar \& Hahn, 2009; Martin \& Yurukoglu, 2017). Moreover, the public media outlet, PBS, a network channel, CBS, and a public service cable channel, C-SPAN, were selected for a more comprehensive comparison.

The researchers chose televised presidential debates as target political content because the political subtends are identical from the outset but are partially mediated by competing broadcasting platforms in order to investigate the different methods partisan media utilize to alter the viewing experience. The entire series of televised presidential debates between Obama and Romney sponsored by the Commission on Presidential Debates in the 2012 election were tested and analyzed to better understand the patterns of the partisan media outlets in covering identical events in ways that render a uniquely consistent political message dependent on media outlets.

The current study was two-fold. The first part was the analysis of debate coverage style. The main purpose of the style coding was to see how much attention each media outlet intended to give to the Democratic and Republican Party candidates. In observing different elements of partisan media's live debate coverage, the techniques in which the debate coverage was represented by the five broadcast organizations were coded. The researchers measured how long and how closely each candidate or both candidates were shown in each media outlet and whether there were any altered treatments or additional information in the debate coverage across different media outlets. In other words, the length of different camera shots and angles were counted and special treatments and supplementary information were analyzed.

For the coverage style analyses, the screen shots were broken down into several categories depending on the purposive camera angle and intentionally favorable shot. The researchers adopted the categories of different camera shots (Close vs. Long) and angles (Front vs. Side vs. Back) from previous debate analysis studies that were continuously used by other subsequent studies (Messaris et al., 1979; Morello, 1988a, 1988b; Tiemens, 1978). The specific coding categories were: both candidates on a split screen, Obama shown larger than Romney or vice versa on the same screen, both candidates on the whole stage, Obama alone close-up vs. Iong shots, Romney alone close-up vs. long shots, moderators shots while they were asking questions and while candidates were answering questions, and specific audience close-up vs. wide audience shots. First, the researchers recorded the amount of time the camera showed each candidate equally sized on a "split screen." Secondly, the amount of footage showing both candidates at the same time with one candidate larger than the other were measured. The researchers counted the time networks showed Obama in the foreground, larger than Romney who was present in the background, and the other way around. Third, the time amounts for when the whole stage was present in the shot, including 
both candidates at the same time but no significant difference in perspective for either candidate were considered. Fourth, single candidate shots that solely showed only Obama or only Romney were counted. These shots were divided between close-up shots where the candidate was only shown from the chest up and long shots where the candidate's whole body was shown from some distance. In this category, only shots where at least half or more of the candidate's face was visible were counted. If you could only see the candidate's back or a small portion of the face then it was categorized as an audience shot. Fifth, shots of moderators were categorized as shown while they were asking questions or while the candidates were speaking. Lastly, the final category of shots recorded was audience shots. These audience shots were divided into close-up shots of a particular audience member and longer shots of a group of audience members. As part of coverage techniques, additional information some media outlets displayed during the debates were coded separately: whether names and affiliations of moderators and questioners were presented; whether debate questions were presented; whether speaking time was tracking; and whether any audience rating was presented while candidates were speaking. Two coders coded the three presidential debate coverage across CNN, FOX, PBS, CBS, and C-SPAN. The Alpha intercoder reliability achieved .98 of the consistency.

The second part were the main experiment tests, to observe whether viewers who were exposed to different partisan media outlets perceived different meaning from the identical political content and evaluated the two party candidates differently. Experiment participation was voluntary and the participants were recruited in general, large elective classes in one of the southern universities. The participants were randomly assigned to different rooms to watch live debates broadcasted by different media outlets. Real-time experimental setting was required to assure that the participants were able to pay close attention to the televised debates in order for them to fully absorb the effects of intended broadcasting techniques they viewed without exposure to pre- or post-debate commentaries. Before and after the participants watched the assigned debate, they were asked to access the candidates on a 100-point feeling thermometer scale.

\section{Findings}

\section{Patterns of Partisan Media Broadcasting Techniques}

Based on the debate formats and rules by the Commission on Presidential Debates, the first debate on October 3 about domestic policy was moderated by Jim Lehrer and each candidate had two minutes to respond to each question. The second debate on October 16 about foreign and domestic policy was a town meeting format in which voters asked questions and each candidate had two minutes to respond to each question. Bob Schieffer moderated the last debate on October 22 about foreign policy and the format was identical to the first debate. One thing to keep in mind is that the dynamics of a town hall style debate may present very different visual presentations and therefore nonverbal dynamics than traditional podium style debates by the very nature of the format, so the data for the second debate may vary from the first and third debates (McKinney \& Carlin, 2004, p. 218). There were some variations in each media outlet's debate coverage techniques depending on the formats and rules of the different debates, however there were distinctive and consistent differences among the media outlets, CNN, FOX, PBS, CBS, and C-SPAN, over the series of the different debates.

CNN was the only channel that presented the exact questions statements while candidates were answering the questions with the candidates' speaking time in an overlay on the screen. Moreover, it was the only channel to show viewers' approval rating during the live debates. During the first debate, it showed two instantaneous approval rating lines by undecided men and women from Colorado where the debate took place. During the broadcasting of the second and third debates, CNN also showed the same rating lines from undecided voters in New York and Florida respectively where 
the second and third debate took place. The screen was relatively static keeping the split shot between the two candidates during most of the debates. However, although CNN spent very little time on each candidate's close-up shot in the traditional podium style debates, Obama's close-up time was about $62 \%$ longer than Romney's in the town meeting format in the second debate (see Table 1).

FOX showed two party candidates in a very different manner in two different camera shots and angles. In the whole stage shot showing both candidates at the same time, it showed both candidates equally from the front center of the stage or from a side angle that showed Romney's front but Obama's side. However, interestingly in those whole stage shots, FOX never showed a single shot of Obama's front with Romney's side. In addition, in the equally split screen shot showing both candidates, the camera angles for Romney and Obama were set differently. In the split screen, when the candidates looked toward the moderators, the angle of Romney was a straight front shot, but the camera angle on Obama was such that he was facing away from Romney. The angles created the perception that Obama was looking away from Romney when Romney was speaking although Obama was looking at the moderators (see Table 1).

Interestingly, CBS repeated one of the same techniques that FOX used. Again, in the whole stage shots, CBS broadcasted the stage in only two ways, one from the center front showing both candidates equally and the other from an angle showing Romney's front and Obama's side but never Obama's front and Romney's side. In addition, especially in the third debate, the camera stayed about $44 \%$ longer on Romney's closeup than Obama's close-up (see Table 1).

PBS was one of the channels that were most diligent in camera shots and angle movements to catch candidates' statements, indications, and gestures. For example, when Romney indicated Obama in his statement, the camera shot quickly changed to show Obama momentarily and came back to Romney again. Even when one candidate was talking, the camera shot kept moving from the side to the front of the candidate's face. It seemed to create more dynamic and interactive meanings of the debates and make both candidates appear more energetic and responsive (see Table 1).

C-SPAN also presented the exact questions asked in the bottom of the screen at least in the beginning of candidates' answers. One noticeable technique was in the equally split shots in the first and last debates. When both candidates were presented in the equally divided split space, the angels for both candidates were the same, but the camera shot was a little bit more zoomed in for Obama than for Romney. Therefore, in the split screen shot, Obama looked a bit larger and closer and often his shoulder line was higher than Romney's. However, in the second debate with the town meeting format, C-SPAN broadcasted about 7\% longer time span on Romney's close-up than on Obama's closeup (see Table 1).

Table 1. Partisan media broadcasting

\begin{tabular}{llllll}
\multicolumn{7}{c}{ techniques } \\
\hline 1st Presidential & $\mathrm{C}$ & $\mathrm{F}$ & $\mathrm{P}$ & $\mathrm{C}$ & $\mathrm{C}-$ \\
Debate & $\mathrm{N}$ & $\mathrm{O}$ & $\mathrm{B}$ & $\mathrm{B}$ & $\mathrm{SPA}$ \\
$(10 / 3 / 12)$ & $\mathrm{N}$ & $\mathrm{X}$ & $\mathrm{S}$ & $\mathrm{S}$ & $\mathrm{N}$ \\
\hline \hline & 5 & & & 2 & \\
& 1 & 7 & & 2 & \\
Equal/Split & 5 & 6 & & 6 & 502 \\
Obama Larger & 9 & 3 & 0 & 3 & 2 \\
Romney Larger & 0 & 0 & 0 & 0 & 0 \\
& 0 & 0 & 0 & 0
\end{tabular}

$\begin{array}{llll}2 & 5 & 6 & 4\end{array}$

$\begin{array}{lllll}\text { Whole Stage } & 3 & 6 & 7 & 2\end{array}$

$\begin{array}{llllll} & & 2 & 2 & 1 & \\ & & 1 & 6 & 4 & \\ & & 3 & 5 & 4 & \\ \text { Obama Close } & 4 & 3 & 6 & 0 & 128 \\ \text { Obama Long } & 3 & 0 & 0 & 0 & 0\end{array}$




\begin{tabular}{|c|c|c|c|c|c|c|c|c|c|c|c|}
\hline & & 1 & 2 & 1 & & & & 1 & 4 & 0 & \\
\hline & & 7 & 0 & 1 & & & 1 & 1 & 1 & 1 & \\
\hline & & 6 & 6 & 9 & & & 0 & 0 & 6 & 4 & \\
\hline Romney Close & 0 & 4 & 3 & 2 & 132 & Romney Long & 1 & 2 & 2 & 1 & 121 \\
\hline Romney Long & 5 & 0 & 0 & 0 & 0 & & & & & & \\
\hline & & & & & & & 1 & 1 & 1 & 1 & \\
\hline & 2 & 4 & 5 & 5 & & & 4 & 9 & 5 & 9 & \\
\hline & 6 & 7 & 2 & 0 & & Mod. Asking & 0 & 5 & 7 & 2 & 166 \\
\hline Mod. Asking & 5 & 4 & 9 & 3 & 153 & & & & 1 & & \\
\hline Mod. Listening & 0 & 2 & 4 & 7 & 0 & Mod L ictoning & 7 & $\begin{array}{l}7 \\
0\end{array}$ & $\begin{array}{l}2 \\
7\end{array}$ & $\begin{array}{l}5 \\
7\end{array}$ & 86 \\
\hline Audience Close & 0 & 0 & 0 & 0 & 0 & & & & & & \\
\hline Audience Group & 0 & 0 & 0 & 0 & 0 & & $\begin{array}{l}1 \\
7\end{array}$ & $\begin{array}{l}1 \\
7\end{array}$ & 0 & $\begin{array}{l}2 \\
0\end{array}$ & \\
\hline & & & & & & Audience Close & 4 & 1 & 4 & 5 & 200 \\
\hline Name & & & & & & & 2 & 3 & 2 & 2 & \\
\hline Moderator & Ye & $\mathrm{Y}$ & $Y$ & $Y$ & & & 4 & 4 & 6 & 6 & \\
\hline Questioner & $\mathrm{s}$ & es & es & es & Yes & Audience Group & 6 & 3 & 5 & 8 & 271 \\
\hline Question & Ye & $\mathrm{N}$ & $\mathrm{N}$ & $\mathrm{N}$ & & & & & & & \\
\hline Statement & $\mathrm{s}$ & 0 & 0 & 0 & Yes & Name & & & & & \\
\hline & Ye & $\mathrm{N}$ & $\mathrm{N}$ & $\mathrm{N}$ & & Moderator & Ye & $\mathrm{Y}$ & $\mathrm{N}$ & $\mathrm{Y}$ & \\
\hline Viewer Rating & $\mathrm{s}$ & 0 & 0 & 0 & No & Questioner & $\mathrm{s}$ & es & 0 & es & No \\
\hline & Ye & $\mathrm{N}$ & $\mathrm{N}$ & $\mathrm{N}$ & & Question & Ye & $\mathrm{N}$ & $\mathrm{N}$ & $\mathrm{N}$ & \\
\hline Speaking Time & $\mathrm{s}$ & 0 & 0 & 0 & No & Statement & $\mathrm{S}$ & 0 & 0 & 0 & Yes \\
\hline & & & & & & & Ye & N & $\mathrm{N}$ & $\mathrm{N}$ & \\
\hline 2nd Presidential & $\mathrm{C}$ & $F$ & $P$ & C & C- & Viewer Rating & $\mathrm{S}$ & 0 & 0 & 0 & No \\
\hline Debate(10/16/1 & $\mathrm{N}$ & $\mathrm{O}$ & B & B & SPA & & Ye & $\mathrm{N}$ & $\mathrm{N}$ & $\mathrm{N}$ & \\
\hline 2) & $\mathrm{N}$ & $\mathrm{X}$ & $\mathrm{S}$ & $\mathrm{S}$ & $\mathrm{N}$ & Speaking Time & $\mathrm{s}$ & 0 & 0 & 0 & No \\
\hline & 1 & & & & & & & & & & \\
\hline & 5 & 1 & & & & 3rd Presidential & $\mathrm{C}$ & $\mathrm{F}$ & $P$ & $\mathrm{C}$ & C- \\
\hline & 8 & 7 & & & & Debate & $\mathrm{N}$ & $\mathrm{O}$ & B & $B$ & SPA \\
\hline Equal/Split & 8 & 8 & 0 & 0 & 0 & $(10 / 22 / 12)$ & $\mathrm{N}$ & $\mathrm{X}$ & $\mathrm{S}$ & $\mathrm{S}$ & $\mathrm{N}$ \\
\hline & 4 & 4 & 4 & 4 & & & 5 & 2 & & 4 & \\
\hline & 2 & 5 & 2 & 3 & & & 1 & 4 & 3 & 0 & \\
\hline Obama Larger & 8 & 8 & 5 & 7 & 415 & & 5 & 6 & 0 & 8 & 541 \\
\hline & 2 & 3 & 2 & 3 & & Equal/Split & 5 & 8 & 6 & 4 & 4 \\
\hline Romney Laraer & $\begin{array}{l}0 \\
6\end{array}$ & $\begin{array}{l}0 \\
7\end{array}$ & $\begin{array}{l}4 \\
2\end{array}$ & $\begin{array}{l}6 \\
8\end{array}$ & 296 & Obama Larger & 0 & 0 & 0 & 5 & 0 \\
\hline 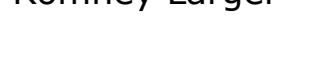 & 2 & 3 & 2 & 4 & & Romney Larger & 0 & 8 & 0 & 2 & 0 \\
\hline & 8 & 7 & 7 & 2 & & & 4 & 9 & & 7 & \\
\hline Whole Stage & 6 & 9 & 0 & 9 & 267 & Whole Stage & 4 & 4 & 0 & 6 & 30 \\
\hline & 1 & 1 & 1 & 1 & & & & 1 & 2 & & \\
\hline & 3 & 6 & 6 & 5 & & & & 3 & 4 & 3 & \\
\hline & 5 & 0 & 5 & 9 & 174 & & 1 & 2 & 2 & 9 & \\
\hline Obama Close & 4 & 7 & 8 & 7 & 3 & Obama Close & 9 & 1 & 5 & 0 & 2 \\
\hline & 1 & 1 & 2 & 1 & & Obama Long & 0 & 2 & 0 & 2 & 0 \\
\hline & 9 & 4 & 0 & 9 & & & & & & & \\
\hline Obama Long & 6 & 0 & 6 & 9 & 198 & & & 1 & 2 & & \\
\hline & & & & & & & & 2 & 3 & 5 & \\
\hline & 8 & 1 & 1 & 1 & & & 1 & 2 & 7 & 6 & \\
\hline & 3 & 6 & 9 & 7 & 186 & Romney Close & 0 & 0 & 1 & 0 & 1 \\
\hline Romney Close & 7 & 7 & 1 & 4 & 7 & Romney Long & 0 & 2 & 0 & 4 & 0 \\
\hline
\end{tabular}




\begin{tabular}{|c|c|c|c|c|c|c|c|c|c|c|c|}
\hline & 3 & 4 & 4 & 3 & & Question & $\mathrm{Ye}$ & $\mathrm{N}$ & $\mathrm{N}$ & $\mathrm{N}$ & \\
\hline & 1 & 5 & 4 & 9 & & Statement & $\mathrm{s}$ & 0 & 0 & 0 & Yes \\
\hline Mod. Asking & 2 & 2 & 7 & 9 & 93 & & $\mathrm{Ye}$ & $\mathrm{N}$ & $\mathrm{N}$ & $\mathrm{N}$ & \\
\hline & & & & 1 & & Viewer Rating & $\mathrm{s}$ & 0 & 0 & 0 & No \\
\hline Mod. Listening & 0 & 0 & 0 & 3 & 0 & & Ye & $\mathrm{N}$ & $\mathrm{N}$ & $\mathrm{N}$ & \\
\hline & & & & & & Speaking Time & $\mathrm{s}$ & 0 & 0 & 0 & No \\
\hline Audience Close & 0 & 0 & 0 & 0 & 0 & *Unit in Sec. & & & & & \\
\hline Audience Group & 0 & 0 & 0 & 0 & 0 & & & & & & \\
\hline Name & Ye & $\mathrm{Y}$ & $Y$ & $\mathrm{Y}$ & & & & & & & \\
\hline Moderator & $\mathrm{s}$ & es & es & es & Yes & & & & & & \\
\hline
\end{tabular}

\section{I mpact of Partisan Media Broadcasting Techniques in Voters' Evaluations of Political Candidates}

Regarding that each live debate was 90 minutes long and the experiment participation was voluntary, many respondents did not complete watching debate and filling out especially post debate survey questions. As the result, the experiment ended up with an uneven number of valid survey respondents across different media outlet exposures. Out of the total valid sample of 253, 143 participants viewed the debates via CNN and successfully completed the surveys, and only 52 FOX channel viewers, 28 CBS channel viewers, 22 C-SPAN viewers, and 8 PBS channel viewers completed the experiments. In order to overcome the unequal sample size, the weighting function was utilized, the weights of $1.769,4.865,31.625,9.036$, and 11.5 were assigned to CNN, FOX, PBS, CBS, and C-SPAN respectively. In the comparison of the different broadcasting techniques by those five channels over the three presidential debates, two-way ANOVA (Analysis of Variance) tests were utilized.

Changes in Obama evaluation

As expected, different partisan media outlets and their broadcasting techniques gave voters different perceptions of the debate content, and the voters' candidate evaluations variously changed by different channel viewership. The ANOVA and Scheffe Post Hoc tests confirmed that CNN $(M=3.69, \mathrm{SE}=0.71)$ and $\mathrm{C}-\mathrm{SPAN}(\mathrm{M}=3.27, \mathrm{SE}=0.41)$ viewers' positive ratings of Obama increased more significantly than FOX $(M=0.58, S E=0.77)$ and PBS $(M=0, S E=0)$ viewers $(F=3.53, p \leq .01)$. In addition, there were some variations across different debates $(F=8.44, p \leq .01)$. C-SPAN viewers $(M=11.67, S E=1.78)$ during the first debate, $C N N$ viewers during the second $(M=4.67, S E=1.11)$ and third $(M=4.37$, $\mathrm{SE}=0.94$ ) debates most distinctively increased their positive ratings towards Obama compared to other channel viewers in other debates. The longer and closer camera shots for Obama over Romney in CNN and C-SPAN broadcasting seemed to make significant differences in the voters' evaluations of the candidates (see Tables 1, $2 \& 3$ ).

Changes in Romney evaluation

The partisan media outlet effects $(F=6.43, p \leq .01)$ and the variations across different debates $(F=8.44, p \leq .01)$ were still statistically significant when it came to Romney's evaluations. As discussed in the partisan media, in contrasts to Obama evaluations, the participants who viewed the debates via FOX $(M=2.83, S E=0.69)$ and CBS $(M=4.14$, $\mathrm{SE}=0.81$ ) channels more significantly increased their positive evaluation of Romney compared to the CNN (M=-0.64, SE=0.84) and PBS $(M=-1.25, \mathrm{SE}=0.21)$ viewers (see Tables 1, 2 \& 3).

According to previous research, in general, televised debates tend to increase voters' political interests and their positive evaluations of the presented candidates. However, the experiment participants who watched the first debate $(M=-11.67, \mathrm{SE}=1.78)$ and the 
third debate $(M=-1.00, S E=0.01)$ on $C$-SPAN became significantly more negative about Romney than other channel debate viewers and his rating actually decreased after viewing the debate via C-SPAN. Interestingly, the C-SPAN viewers $(M=4.67, S E=0.82)$ during the second debate, however, increased their positive Romney evaluation most than any other channel viewers. It clearly reflected C-SPAN's different debate coverage patterns and techniques over the three debates. As analyzed above, the relatively smaller and longer shots for Romney during the first and third debates and the longer time span on Romney's close-up shots during the second debate seemed to be the cause of the dramatic rating changes to the opposite directions (see Tables 1, $2 \& 3$ ).

CBS viewers during the first debate $(M=4.19, S E=0.84)$, when $C B S$ showed relatively more Romney-favored front shots having Obama side views, and FOX viewers during the third debate $(M=1.58, S E=0.83)$, where the channel paid more distinctive attention on Romney's favorable inward angles over Obama's outward angle, evaluated Romney more positively than any other channel viewers at any other debate, and the broadcasting techniques seemed to contribute to increasing Romany's rating (see Tables 1, 2 \& 3).

\section{Changes in relative evaluations between Obama and Romney}

In the comparative political contents and settings like the televised presidential debates, voters sought to compare their candidates, and their evaluations toward the competing candidates are often related. For example, if a voter starts viewing a candidate in a more positive way, the voter tends to evaluate the opposing candidate more negatively (Yun, Jasperson, \& Kaid, 2010). Therefore, the researchers also looked into how relative preference of a candidate over the opposing candidate had changed by the exposure to the broadcasting techniques adopted by the different partisan media outlets. The relative preference measure was accessed using Obama's relative evaluations to Romney's by subtracting changes in Romney's feeling thermometer scores from changes in Obama's scores after debate viewing, having positive values for relative preference changes toward Obama over Romney and negative values for relative preference changes toward Romney over Obama. Again, the ANOVA and post hoc tests confirmed that the partisan media's broadcasting strategies covering the partly-mediated political contents made differences on voters' relative assessment of the competing candidates $(F=8.10, p \leq .01)$ and the degrees of changes somewhat varied by different debates $(F=19.41, p \leq .01)$. As to what the partisan broadcasting strategies intended, CNN viewers' $(M=4.33, S E=1.25)$ relative preference toward Obama over Romney, and FOX $(M=-2.25, \mathrm{SE}=1.25)$ and CBS $(\mathrm{M}=-1.18, \mathrm{SE}=0.88)$ viewers' relative preference toward Romney against Obama increased more significantly after viewing debates compared to any other channel viewers. C-SPAN viewers during the first debate $(M=23.33, S E=3.55)$ and $C N N$ viewers during the second $(M=5.59, S E=1.92)$ and third $(M=5.73, S E=1.74)$ debates more significantly increased their relative preference toward Obama over Romney, while CBS and C-SPAN viewers during the second debate and Fox viewers during the third debate became relatively more positive about Romney compared to the positive changes in Obama than other channel viewers in other debates (see Tables $1,2 \& 3$ ). 
Table 2. Mean changes in candidate evaluations by partisan media broadcasting techniques

\begin{tabular}{|c|c|c|c|c|c|c|c|}
\hline \multirow[b]{2}{*}{ Debate } & \multirow[b]{2}{*}{ Channel } & \multicolumn{4}{|c|}{ Changes in Obama Rating Changes in Romney Rating } & \multicolumn{2}{|c|}{ Changes in Relativism } \\
\hline & & Mean & $\mathrm{SE}$ & Mean & $\mathrm{SE}$ & Mean & SE \\
\hline \multirow[t]{6}{*}{ 1st Presidential Debate } & CNN & -1.58 & 2.53 & 2.89 & 2.11 & -4.47 & 3.80 \\
\hline & FOX & 1.42 & 1.79 & 5.89 & 1.51 & -4.47 & 2.78 \\
\hline & PBS & * & * & * & * & $*$ & * \\
\hline & CBS & 3.07 & 0.81 & 4.19 & 0.84 & -1.11 & 0.91 \\
\hline & C-SPAN & 11.67 & 1.78 & -11.67 & 1.78 & 23.33 & 3.55 \\
\hline & Total & 3.04 & 0.70 & 3.12 & 0.69 & -0.07 & 1.01 \\
\hline \multirow[t]{6}{*}{ 2nd Presidential Debate } & CNN & 4.67 & 1.11 & -0.92 & 1.53 & 5.59 & 1.92 \\
\hline & FOX & 0.00 & 1.03 & 0.36 & 0.88 & -0.36 & 1.85 \\
\hline & PBS & * & * & * & * & $*$ & * \\
\hline & CBS & 0.00 & 0.00 & 3.00 & 0.00 & -3.00 & 0.00 \\
\hline & C-SPAN & 2.00 & 0.31 & 4.67 & 0.82 & -2.67 & 0.88 \\
\hline & Total & 2.21 & 0.37 & 2.53 & 0.61 & -0.32 & 0.76 \\
\hline \multirow[t]{6}{*}{ 3rd Presidential Debate } & CNN & 4.37 & 0.94 & -1.36 & 1.13 & 5.73 & 1.74 \\
\hline & FOX & 0.16 & 0.80 & 1.58 & 0.83 & -1.42 & 1.43 \\
\hline & PBS & 0.00 & 0.00 & -1.25 & 0.21 & 1.25 & 0.21 \\
\hline & CBS & * & * & * & * & $*$ & * \\
\hline & C-SPAN & 1.00 & 0.00 & -1.00 & 0.00 & 2.00 & 0.00 \\
\hline & Total & 1.24 & 0.31 & -0.74 & 0.36 & 1.98 & 0.56 \\
\hline \multirow[t]{6}{*}{ Total } & CNN & 3.69 & 0.71 & -0.64 & 0.84 & 4.33 & 1.25 \\
\hline & FOX & 0.58 & 0.77 & 2.83 & 0.69 & -2.25 & 1.25 \\
\hline & PBS & 0.00 & 0.00 & -1.25 & 0.21 & 1.25 & 0.21 \\
\hline & CBS & 2.96 & 0.78 & 4.14 & 0.81 & -1.18 & 0.88 \\
\hline & C-SPAN & 3.27 & 0.41 & 2.18 & 0.79 & 1.09 & 1.03 \\
\hline & Total & 2.10 & 0.28 & 1.45 & 0.32 & 0.65 & 0.45 \\
\hline
\end{tabular}

Table 3. ANOVA Tests on changes in candidate evaluations by partisan media broadcasting techniques

\begin{tabular}{l|rr|rr|r|r|}
\hline & \multicolumn{2}{|c|}{ Obama Evaluation } & \multicolumn{2}{c|}{ Romney Evaluation } & \multicolumn{2}{c}{ Relative Evaluation } \\
\hline \hline Source & $\mathrm{F}$ & Sig. & $\mathrm{F}$ & Sig. & $\mathrm{F}$ & Sig. \\
\hline Corrected Model & 7.24 & 0.00 & 11.97 & 0.00 & 12.28 & 0.00 \\
\hline Intercept & 21.04 & 0.00 & 1.24 & 0.27 & 4.26 & 0.04 \\
\hline Debate & 1.99 & 0.14 & 0.78 & 0.46 & 1.91 & 0.15 \\
\hline Media Outlets & 3.53 & 0.01 & 6.43 & 0.00 & 8.10 & 0.00 \\
\hline Debate* Media Outlets & 8.44 & 0.00 & 15.93 & 0.00 & 19.41 & 0.00 \\
\hline & \multicolumn{7}{|c|}{$\mathrm{R}^{2}=.057$} & $\mathrm{R}^{2}=.092$ & \multicolumn{3}{c|}{$\mathrm{R}^{2}=.094$} \\
\hline
\end{tabular}

\section{Conclusion}

The partisan media outlets and their political effects are less explored areas of research and practically very controversial and tender topics. The current study confirmed that partisan media outlets utilize various broadcasting techniques and strategies to deliver the partly-mediated political information within the context of their political intentions. In future studies, the researchers will further investigate to find different dimensions of the partisan media outlet effects such as on viewers' political information efficacy and polarization beyond the effects on candidate evaluations. The current study reemphasizes the importance of accurate and balanced broadcasting techniques to appropriately inform the public without intended bias. 
The limitation of the current study is the unbalanced sample size in different media outlet exposures and the student samples. However, previous researchers have confirmed that the weighting function corrects the uneven sample size with high reliability and validity as proven by the National Election Studies (NES) that have used the method to correct their uneven sample cases. In addition, continuous research using student samples and the following meta analyses with those studies found that the statistical test effects are not much different between student and non-student general public samples (Benoit, Hansen, \& Verser, 2003, p. 340). Despite, future studies with a more robust quality and size of general public sample are needed to provide a more generalizable argument regarding the effects of partisan media outlets in American politics and further to suggest normative and practical modifications to McLuhan's classic theory in the new media system era.

\section{Reference}

Benoit, W. L., Hansen, G. J., \& Verser, R. M. (2003). A meta-analysis of the effects of viewing U.S.

presidential debates. Communication Monographs, 70(4), 335-350.

Carpenter, M. (2006, December 11). Anchor Olbermann counts on commentary to boost MSNBC's ratings. Pittsburgh Post Gazette. Retrieved from http://www.postgazette.com/pg/06346/745336-237.stm.

Commager, H. S. (1960, October 30). Washington would have lost a TV debate. New York Times Magazine, VI-13, 46.

D'Alessio, D., \& Allen, M. (2000). Media Bias in Presidential Elections: A Meta-Analysis. J ournal of Communications, 50(4), 133-156.

David J. L. \& Peter R. S, (1991). The J oint Press Conference: The History, Impact and Prospects of

American Presidential Debates. New York, NY: Greenwood.

Davis, L. K. (1978). Camera-eye contact by the candidates in the presidential debates of 1976. Journalism Quarterly, 55(3), 583-585.

Doll, H. D., \& Bradley, B. E. (1974). A study of the objectivity of television news reporting of the 1972 presidential campaign. Central States Speech J ournal, 25(4), 254-263.

Durkheim, E. (1995). The elementary forms of religious life (K. E. Fields, Tran.). New York, NY: Free Press.

Entman, R. M. (2005). The nature and sources of news. In Geneva Overholser \& Kathleen H. Jamieson (Eds.), The Institutions of American Democracy: The press (pp. 48-65). New York, NY: Oxford University Press.

Grabe M. E., Bucy, E. P. (2009). Image bite politics: News and the visual framing of elections. New York,

NY: Oxford University Press.

Hastorf, A. H., \& Cantril, H. (1954). They saw a game: A case study. Journal of Abnormal and Social Psychology. 49(1), 129-134.

Hellweg, S., \& Phillips, S. (1981). A verbal and visual analysis of the 1980 Houston Republican presidential primary debate. Southern Speech Communication J ournal, 47(1), 23-38.

Hellweg, S. A., Pfau, M., \& Brydon, S. R. (1992). Televised presidential debates: Advocacy in contemporary America. Westport, CT: Greenwood.

Hofstetter, C. R. (1976). Bias in the news: Network television coverage of the 1972 election campaign. Columbus: Ohio State University Press.

Holbrook, T. M. (1999). Political learning from the presidential debates. Political Behavior, 21(1), 67-89.

Iyengar, S., \& Hahn, K. S. (2009). Red media, blue media: Evidence of ideological selectivity in media use. Journal of Communication, 59(1), 19-39.

Klein, M. W., \& Maccoby, N. (1954). Newspaper objectivity in the 1952 campaign. J ournalism Quarterly, 31(3), 285-296. 
Kraus, S. (1988). Televised Presidential Debates and Public Policy. Hillsdale, N.J.: Lawrence Erlbaum.

Lang, K. (1968). Politics and Television. Chicago, IL: Quadrangle.

Martin, G. J., \& Yurukoglu, A. (2017). Bias in cable news: Persuasion and polarization. American Economic Review, 107(9), 2565-2599.

McKinney, M. S., \& Carlin, D. B. (2004). Political Debates. Handbook of Political Communication Research. Mahwah, NJ: Lawrence Erlbaun Associates.

McLuhan, M. (1964). Understanding Media: The Extensions of Man. New York, NY: McGraw-Hill.

McLuhan, M., Fiore, Q., \& Agel, J. (1967). The Medium is the Massage: An Inventory of Effects. New York, NY: Bantam.

Media Studies Center-Roper Center (1996). How the public uses the media. Retrieved from https://ropercenter.cornell.edu/public-perspective/ppscan/76/ 76011.pdf.

Messaris, P., Eckman, B., \& Gumpert, G. (1979). Editing structure in the televised versions of the 1976 presidential debates. Journal of Broadcasting, 23(3), 259-369.

Morello, J. T. (1988a). Visual structuring of the 1976 and 1984 nationally televised presidential debates: Implications. Central Studies Speech Journal, 39(3), 233243.

Morello, J. T. (1988b). Argument and visual structuring in the 1984 Mondale- Reagan debates: The Medium's influence on the perception of clash. Western J ournal of Speech Communication. 52(4), 277-290.

Morello, J. T. (1992). The "look" and language of clash: Visual structuring of argument in the 1988 Bush-Duakakis debates. Southern Communication Journal, 57(3), 205218.

Morley, D. (2004). Broadcasting and the construction of the national family. In Robert C. Allen and Annette Hill (Eds.), The television studies reader (pp. 418-441). London, U.K.: Routledge.

Nielsen Media. (2012, October 23). Final Presidential Debate Draws 59.2 Million Viewers. Newswire. Retrieved from http://www.nielsen.com/us/en/insights/news/2012/finalpresidential-debate-draws-59-2-million-viewers.html.

Nixon, R. (1978). RN: The Memoirs of Richard Nixon. New York, NY: Grossett and Dunlap.

Peters, J. W. (2012, October 9). Networks Like Split-Screens in Debates, Even If the Candidates Don't. New

York Times. Retrieved from http://www.nytimes.com/2012/10/10/us/politics/networkslike-split-screens-in-debates-even-if-candidates-dont.html?_r=1.

Pew Research Center. (2012, November 2). Winning the Media Campaign. J ournalism and Media.

Retrieved from http://www.journalism.org/2012/11/02/winning-media-campaign-2012/.

Project for Excellence in Journalism. (2005). The state of the news media 2005: An annual report on American journalism. State of the Media. Retrieved from http://www.stateofthemedia.org/2005/.

Project for Excellence in Journalism. (2007). The state of news media 2007: An annual report on American journalism. State of the Media. Retrieved from http://www.stateofthemedia.org/2007/.

Rothkopf, E. Z., Dixon, P. \& Billington, M. J. (1986). Effects of enhanced spatial context on television message retention. Communications Research, 13(1), 55-69.

Scheufele, D. A., Kim, E., \& Brossard, D. (2007). My friend's enemy: How split-screen debate coverage influences evaluation of presidential debates. Communication Research, 34(1), 3-24.

Schneider, W., \& Lewis, I. A. (1985). Views on the news. Public Opinion, 8(4), 6-11.

Schroeder, A. (2008). Presidential Debates: Fifty Years of High-risk TV (2 ${ }^{\text {nd }}$ ed.). New York, NY: Columbia

University Press. 
Stempel, G. H., \& Windhauser, J. W. (1989). Coverage by the prestige press of the 1988 presidential campaign. Journalism Quarterly, 66(4), 894-869.

Stevenson, R. L., \& Greene, M. T. (1980). A reconsideration of bias in the news. J ournalism Quarterly,

57(1), 115-121.

Tiemens, R. K. (1978). Televisions portrayal of the 1976 presidential debates: An analysis of visual content. Communications Monographs, 45(4), 362-370.

Tiemens, R. K., Hellweg, S. A., Kipper, P., \& Phillips, S. L. (1985). An integrated verbal and visual analysis of the Carter-Ford Debate. Communications Quarterly, 33(1), 34-43.

White, D. M. (1950). The gate-keeper: A case study in the selection of news. Journalism Quarterly, 27(3), 383-390.

Williams, A. (1975). Unbiased study of television news bias. Journal of Communications, 25(4), 190-199.

Yun, H. J., Jasperson, A., \& Kaid, L. L. (2010). The cumulative effects of televised presidential debates on voters' attitudes across red, blue, and purples political playgrounds. In Mitchell S. McKinney \& Mary C. Banwart (Eds.), Communication in the 2008 U.S. election: Digital natives elect a president (pp. 107-120). New York, NY: Peter Lang Publishing, Inc. 